\title{
Can we now recommend OTSC as first-line therapy in case of non-variceal upper gastrointestinal bleeding?
}

\section{다(1) $(9)$}

\author{
Authors \\ Shannon Melissa Chan ${ }^{1}$, James YW Lau ${ }^{1,2}$ \\ Institutions \\ 1 Department of Surgery, Prince of Wales Hospital, The \\ Chinese University of Hong Kong, Shatin, Hong Kong, \\ China \\ 2 Institute of Digestive Disease, Prince of Wales Hospital, \\ The Chinese University of Hong Kong, Hong Kong SAR, \\ China.
}

submitted 14.4.2017

accepted after revision: $\quad 2.5 .2017$

\author{
Bibliography \\ DOI https://doi.org/10.1055/s-0043-111722 | \\ Endoscopy International Open 2017; 05: E883-E885 \\ (c) Georg Thieme Verlag KG Stuttgart · New York \\ ISSN 2364-3722
}

Corresponding author

Professor James Yun Wong Lau, Department of Surgery,

Prince of Wales Hospital, The Chinese University of Hong

Kong, Shatin, Hong Kong, China

Fax: +852-263-779-74

laujwy@surgery.cuhk.edu.hk
In the management of patients with acute non-variceal upper gastrointestinal bleeding, endoscopic hemostasis and acid suppression have significantly improved outcomes [1-3]. However, $8 \%$ to $15 \%$ of patients continue to bleed or develop further bleeding $[3,4]$. Further bleeding remains one of the most important predictors of mortality $[3,5,6]$. Research, therefore, has been focused on methods to improve endoscopic hemostasis, and thus mortality.

The standard of care in endoscopic hemostasis is either application of contact thermocoagulation or mechanical therapy such as haemostatic clips [7-9] with or without pre-injection with diluted adrenaline. However, there are limitations to conventional hemostatic methods. In an ex vivo bleeding model using canine mesenteric arteries, endoscopic thermocoagulation could only consistently seal arteries up to $2 \mathrm{~mm}$ [10]. Hemostatic clips achieve hemostasis through mechanical tamponade over the bleeding vessel. However, tangential application of hemostatic clips can be difficult in lesions located in the bulbar duodenum and the lesser curvature of the stomach. Furthermore, the clips often dislodge, leading to recurrent bleeding. Application of clips can also sometimes be difficult in chronic ulcers with a fibrotic base. The Over-The-Scope-Clip (OTSC; Oversco Endoscopy AG, Tübingen, Germany) has been successfully used to close perforations of the gastrointestinal tract and to control gastrointestinal bleeding [11]. With a wider jaw and greater strength, the OTSC has the advantages of a firm grip over a larger amount of tissue. Clip retention is almost universal.
To date, only small-scale retrospective series with the device have been perfomed. Kirschniak et al reported the first clinical experience with OTSC for gastrointestinal bleeding and achieved $100 \%$ primary hemostasis with no rebleeding [12]. In another series including 30 cases in which conventional endoscopic hemostasis had failed, the authors reported a $97 \%$ success rate for primary hemostasis and $6 \%$ rebleeding rate [13]. In our series where we also included cases refractory to conventional endoscopic treatment, we achieved a 10/10 (100\%) success rate for primary hemostasis. However, rebleeding occurred in to $22 \%$ [14]. From the limited data available, a $97 \%$ to $100 \%$ primary success rate was achieved [11-17]. However, the rebleeding rate ranges from $0 \%$ to $22 \%$ [11-17].

In this latest issue of Endoscopy International Open, one of the largest experiences with OTSC in management of patients with nonvariceal upper gastrointestinal bleeding (NVUGIB) has been published. Wedi et al reported their 6-year experience with 100 patients from two academic centers in Germany. In this study, a $94 \%$ success rate for primary hemostasis was reported. However, 3 of the 6 patients in whom initial OTSC placement failed died. Of the 94 patients in whom the procedure succeeded, 5 developed an early rebleed (within 24 hours) and 3 developed a late rebleed ( $\leq 30$ days). Four of these 8 patients died consequently. The mortality following failed OTSC application was high.

In another recently published cohort of 100 patients including treatment of both NVUGIB and lower gastrointestinal bleeding, similar results were found [18]. Sixty-nine patients had NVUGIB treated with OTSC, either as first-line or salvage 
treatment. Primary failure was significantly lower when OTSC was applied as first- line rather than second-line treatment (4.9\% vs $23 \% ; P=0.008)$. In a multivariate analysis, patients who had OTSC placement as second-line treatment had a significantly higher rebleeding risk as compared to those who had OTSC as the first treatment (OR 5.3; $P=0.008)$. This was expected as patients who developed further bleeding after conventional treatment represented a selected group with higher risk of further bleeding. The authors also found that patients with a Rockall score of 7 or greater experienced fewer rebleeding episodes when treated with OTSC (214/457 (46.8\%) vs 8/43 (18.6\%); $P=0.0003)$. They argued for use of OTSC in the highrisk groups. In the series, the rebleeding-associated mortality rate for patients with NVUGIB was $11 \%$. Unsuccessful primary endoscopic hemostasis was found to be an independent risk factor for mortality [19]. These findings underscore the importance of a durable primary control of bleeding

We all know that OTSC, if applied correctly, provides good control. But when does it fail? And how can we improve the success rate? To successfully place the OTSC, an en face view of the bleeding lesion is crucial, which is sometimes difficult to achieve, especially with ulcers located in the posterior wall of the duodenal bulb. OTSC deployment also can be difficult with scope in retroflexion. A technical point is to use a smaller OTSC and an anchoring device to puncture near the bleeding site to guide the OTSC. Moreover, in actively bleeding ulcers, where the base of the vessel was not well seen, pretreatment with adrenaline injection improved visualization.

Schmidt et al. presented final results of the STING trial that enrolled patients with refractory bleeders. The rate of freedom from rebleeding with use of OTSC at day 30 was significantly higher (30.8\% vs $78 \%$; $P=0.004$ ) [20] when compared to conventional treatment with either thermal methods or hemoclips. We eagerly await publication of the full results. Use of OTSC as primary treatment has not been compared to current standards. Such a randomized controlled trial is required. This primary use of OTSC seems logical as further bleeding is associated with substantial mortality $[5,6]$. In a systematic review, factors that predict further bleeding include hemodynamic stability, comorbid illness, active bleeding ulcers, large ulcers, and ulcers at posterior duodenum and lesser curve [21]. These lesions are clear candidates for application of OTSC. Such an approach will also likely benefit patients at high cardiovascular risk or at high risk of further bleeding. Finally, a cost analysis is required. We speculate that the added cost in managing further bleeding after standard treatment likely outweighs the cost of OTSC.

Competing interests

None
References

[1] Cook D], Guyatt GH, Salena B] et al. Endoscopic therapy for acute nonvariceal upper gastrointestinal hemorrhage: a meta-analysis. Gastroenterology 1992; 102: 139-148

[2] Therapeutic endoscopy and bleeding ulcers. Natl Inst Health Consens Dev Conf Consens Statement 1989; 7: 1-7

[3] Laine L, Jensen DM. Management of patients with ulcer bleeding. Am ] Gastroenterol 2012; 107: 345-60; quiz 61

[4] Wong SK, Yu LM, Lau JY et al. Prediction of therapeutic failure after adrenaline injection plus heater probe treatment in patients with bleeding peptic ulcer. Gut 2002; 50: 322 - 325

[5] Marmo R, Koch M, Cipolletta L et al. Predicting mortality in patients with in-hospital nonvariceal upper GI bleeding: a prospective, multicenter database study. Gastrointest Endosc 2014; 79: 741 - 749 e1

[6] Chiu PW, Ng EK, Cheung FK et al. Predicting mortality in patients with bleeding peptic ulcers after therapeutic endoscopy. Clin Gastroenterol Hepatol 2009; 7: 311 - 316; quiz 253

[7] Marmo R, Rotondano G, Piscopo R et al. Dual therapy versus monotherapy in the endoscopic treatment of high-risk bleeding ulcers: a meta-analysis of controlled trials. Am J Gastroenterol 2007; 102: 279-289; quiz 469

[8] Lo CC, Hsu PI, Lo GH et al. Comparison of hemostatic efficacy for epinephrine injection alone and injection combined with hemoclip therapy in treating high-risk bleeding ulcers. Gastrointest Endosc 2006; 63: $767-773$

[9] Gralnek IM, Dumonceau JM, Kuipers E] et al. Diagnosis and management of nonvariceal upper gastrointestinal hemorrhage: European Society of Gastrointestinal Endoscopy (ESGE) Guideline. Endoscopy 2015; 47: a $1-46$

[10] Johnston JH, Jensen DM, Auth D. Experimental comparison of endoscopic yttrium-aluminum-garnet laser, electrosurgery, and heater probe for canine gut arterial coagulation. Importance of compression and avoidance of erosion. Gastroenterology 1987; 92: 1101-1108

[11] Kirschniak A, Subotova N, Zieker D et al. The Over-The-Scope Clip (OTSC) for the treatment of gastrointestinal bleeding, perforations, and fistulas. Surg Endosc 2011; 25: $2901-2905$

[12] Kirschniak A, Kratt T, Stuker D et al. A new endoscopic over-the-scope clip system for treatment of lesions and bleeding in the Gl tract: first clinical experiences. Gastrointest Endosc 2007; 66: 162 -167

[13] Manta R, Galloro G, Mangiavillano B et al. Over-the-scope clip (OTSC) represents an effective endoscopic treatment for acute GI bleeding after failure of conventional techniques. Surg Endosc 2013; 27: $3162-3164$

[14] Chan SM, Chiu PW, Teoh AY et al. Use of the Over-The-Scope Clip for treatment of refractory upper gastrointestinal bleeding: a case series. Endoscopy 2014; 46: 428-431

[15] Repici A, Arezzo A, De Caro G et al. Clinical experience with a new endoscopic over-the-scope clip system for use in the GI tract. Dig Liver Dis 2009; 41: 406-410

[16] Baron TH, Song LM, Ross A et al. Use of an over-the-scope clipping device: multicenter retrospective results of the first U.S. experience (with videos). Gastrointest Endosc 2012; 76: 202-208

[17] Goenka MK, Rai VK, Goenka U et al. Endoscopic Management of Gastrointestinal Leaks and Bleeding with the Over-the-Scope Clip: A Prospective Study. Clin Endosc 2017; 50: 58 - 63

[18] Richter-Schrag H], Glatz T, Walker C et al. First-line endoscopic treatment with over-the-scope clips significantly improves the primary failure and rebleeding rates in high-risk gastrointestinal bleeding: A single-center experience with 100 cases. World J Gastroenterol 2016; 22: $9162-9171$ 
[19] Ogasawara N, Mizuno M, Masui R et al. Predictive factors for intractability to endoscopic hemostasis in the treatment of bleeding gastroduodenal peptic ulcers in Japanese patients. Clin Endosc 2014; 47: $162-173$

[20] Schmidt A, Goelder S, Messmann H et al. Over-the-scope-clips versus standard endoscopic therapy in patients with recurrent peptic ulcer bleeding: Preliminary results of a prospective randomized multicentre trial ("STING"). United European Gastroenterology Journal 2016; 02 (Suppl. 01): doi:10.1016/j.gie.2017.03.043
[21] Elmunzer B], Young SD, Inadomi JM et al. Systematic review of the predictors of recurrent hemorrhage after endoscopic hemostatic therapy for bleeding peptic ulcers. Am J Gastroenterol 2008; 103: 2625-2632; quiz 33

[22] Lau JY, Wong KT, Chiu WY et al. Early Angiographic Embolization After Endoscopic Hemostasis to High Risk Bleeding Peptic Ulcers Improves Outcomes. Gastrointest Endosc 2014; 79: (Suppl. 44): 157 